\title{
Potret dan Segmentasi Mad'u Dalam Perkembangan Media di Indonesia
}

\author{
Asna Istya Marwantika \\ Dosen FUAD IAIN Ponorogo \\ Email: marwantika@iainponorogo.ac.id
}

\begin{abstract}
Abstrak
Artikel ini membahas potret dan segmentasi mad'u/ audien dakwah dalam perkembangan media di indonesia. Menggunakan analisis deskriptif dan konsep audien dari Dennis McQuail ditemukan bahwa aktifitas dakwah pada dasarnya selalu bersifat segmented, dimana pesan dan pola dakwah akan selalu berusaha disesuaikan dengan konteks khalayak. Sejalan dengan itu, aktifitas dan gerakan dakwah telah muncul dan berevolusi dalam beragam bentuk yang dimediasi oleh media massa (media cetak, radio dan televisi) yang bersifat linier dan mengkategorikan mad'unya sebagai audien pasif, sedangkan aktifitas dakwah yang dimediasi media baru (new media) yang bersifat non-linier mengkategorikan mad'unya sebagai audien aktif. Kategori mad'u pasif-mad'u aktif ini juga mempunyai konsekwensi dan tantangannya seperti adanya adaptasi format dakwah di media, komodifikasi agama, pergeseran otoritas keagamaan (da'i), adanya paparan radikalisme, melahirkan hoaks, dan juga telah menjadi echo chambers yaitu ruang gema yang berisi pandangan orang-orang yang beranggapan sama dan satu selera sehingga tidak menghasilkan dialog yang baik.
\end{abstract}

\begin{abstract}
:
This article discusses portrait and segmentation of mad'u / da'wah audience in the development of media in Indonesia. Using descriptive analysis and audience concept from Dennis McQuail it was found that da'wah activities are basically always segmented, where messages and patterns of da'wah will always try to be adapted to the context of the audience. Correspondingly, da'wah activities and movements have emerged and evolved in various forms mediated by the mass media (print, radio and television) which are linear in nature and categorize the medium as a passive audience, while preaching activities mediated by new media (digital) non-linear nature categorizes the madness as an active audience. This active category of mad'u passive-mad'u also has consequences and challenges such as the adaptation of the format of da'wah in the media, the commodification of religion, the shift of religious authority (preachers), the exposure of radicalism, it produce hoaxes, and echo chambers namely echo space that contains the views of people who think the same and one taste so it does not produce a good dialogue.
\end{abstract}

Keyword : Segmentasi Mad'u, Mad'u Aktif-Pasif, Perkembangan Media

\section{PENDAHULUAN}

Perubahan ruang dan waktu, turut memberikan konsekuensi pada perubahan pola, pendekatan, metodologi, dan karakteristik dakwah. Dakwah juga bersifat situasional dan kontekstual sesuai ruang dan waktu yang melingkupinya. Dalam 
konteks tabligh ${ }^{1}$ salah satu unsur yang tidak boleh diabaikan adalah mad'u atau audiens atau khalayak yang merupakan obyek dari aktifitas dakwah baik secara individu maupun kelompok di dalam ruang dan waktu tertentu. Mad'u sekarang tidak hanya identik dengan tradisi oral, tetapi juga tradisi baru yang mengandalkan media.

Proses tabligh dalam keseluruhan sistem dakwah dapat dipandang sebagai ujung tombak karena bukan hanya proses transmisi pesan-pesan agama, melainkan juga upaya untuk memperkenalkan ajaran Islam kepada masyarakat atau khalayak, baik berupa pengajian di majlis taklim, tablig akbar, rubrik agama di surat kabar atau majalah, siaran keagamaan di radio, televisi, film dan semua yang dikenal sebagai media massa adalah aktifitas komunikasi. Istilah tabligh ini lebih identik dengan komunikasi keagamaan dalam konteks public speaking atau broadcasting, namun materi yang disampaikan berisi tentang ajaran Islam. Sifatnya lebih ke insidental, oral, massal, seremonial bahkan kolosal. Kemudian mengalami perkembangan ketika melakukan tabligh di media cetak, radio, televisi maupun new media/digital, hal ini termasuk dinamakan tabligh yang dimediasi.

Penggunaan media dakwah ini menjadi suatu keniscayaan bagi lembaga dakwah maupun da'i agar terpaan pesan-pesan agama lebih menjangkau khalayak luas ataupun masyarakat umum. Namun adopsi dan adaptasi ke berbagai media seperti media cetak, radio, televisi dan new media juga mempunyai konsekwensi seperti terkotakkannya istilah mad'u pasif-mad'u aktif.

\footnotetext{
${ }^{1}$ Aktifitas dakwah Islam dibagi dalam empat kategori besar, yaitu : 1)Tabligh, sebagai upaya penerangan dan penyebaran islam- konteks ini memiliki persinggungan dengan disiplin komunikasi, 2) Irsyad, sebagai upaya bimbingan dan penyuluhan Islam- konteks ini bersinggungan dengan disiplin psikologi dan konseling, 3)Tadbir, sebagai upaya pemberdayaan umat dalam menjalankan ajaran-ajaran Islam melalui lembaga dakwah - konteks ini bersinggungan dengan denfan disiplin manajemen dan organisasi, serta 4) Tathwir atau Tamkin, sebagai upaya pemberdayaan kehidupan ekonomi keumatan dalam masyarakat - konteks ini bersinggungan dengan disiplin sosiologi. Lihat Moch Fakhruroji, Dakwah di Era Media Baru, (Bandung, Simbiosa Rekatama, 2017), hlm.3
} 
Mengapa perkembangan teknologi dan komunikasi sangat menentukan perubahan sosial bahkan aktifitas dakwah di masyarakat ?, kiranya pertanyaan ini akan dijawab dengan beberapa deskripsi aktifitas dakwah dari era teknologi sederhana berupa retorika/tabligh, kemudian beralih ke media massa, dan kemudian di era media baru (digital).

\section{Konsep Mad'u Sebagai Obyek-Mitra Menurut Ilmu Dakwah}

Secara etimologi kata mad'u berasal dari bahasa arab, diambil dari isim maf'ul (kata yang menunjukkan obyek atau sasaran). Menurut terminologi, mad'u adalah orang atau kelompok yang lazim disebut dengan jamaah yang sedang menuntut ajaran agama dari seorang da'i, baik mad'u itu orang dekat atau jauh, muslim atau non muslim, laki-laki atau perempuan. Seorang da'i akan menjadikan mad'u sebagai obyek ${ }^{2}$ bagi transformasi keilmuan yang dimilikinya. Mad'u sebagai obyek dakwah bagi seorang da'i merupakan salah satu unsur yang penting dalam sistem dakwah.

Sebagian besar para ilmuan dakwah mengkategorikan konsep mad'u sebagai obyek dakwah. Obyek dakwah ini meliputi masyarakat dilihat dari berbagai $\operatorname{segi}^{3}$ : a) Sasaran yang menyangkut kelompok masyarakat dilihat dari segi sosiologis berupa masyarakat terasing pedesaan, kota besar dan kecil serta masyarakat di daerah marginal dari kota besar., b) Sasaran yang menyangkut golongan masyarakat dilihat dari sudut struktur kelembagaan berupa masyarakat, pemerintahan dan keluarga.c) Sasaran yang berupa kelompok yang dilihat dari segi sosial kultural berupa golongan priyayi, abangan, santri. Klasifikasi terletak dalam masyarakat Jawa. c) Sasaran yang dilihat dari segi tingkat usia, berupa golongan anak-aanak, remaja dan orang tua., d) Sasaran yang berhubungan dengan golongan profesi atau pekerjaan. e) Sasaran yang menyangkut masyarakat dilihat dari segi tingkat hidup sosial ekonomi. f) Sasaran yang menyangkut kelompok masyarakat yang dilihat dari jenis kelamin., dan g) Sasaran yang

\footnotetext{
${ }^{2}$ Wahidin Saputra, Pengantar lmu Dakwah, (Jakarta ; Raja Grafindo, 2011),hlm. 279-280.

${ }^{3}$ Ibid., hlm. 282
} 
berhubungan dengan golongan yang dilihat dari segi khusus, golongan masyarakat tuna susila, tuna wisma, narapidana.

Berbeda halnya dengan Ali Aziz', mad'u disini diposisikan bukan sebagai obyek atau sasaran dakwah, dengan maksud agar para da'i menjadi kawan berfikir dan bertindak bersama dengan mitra dakwah. Hubungan ideal antara da'i dengan mad'u bukan hubungan subyek-obyek, bukan pula sebagai sasaran yang terkesan pasif dan hanya pendakwah yang aktif. Pendakwah bukan orang yang paling tahu dan paling suci diantara manusia. Oleh sebab itu, dengan kemitraan, kesejajaran antara pendakwah dan mitra dakwah akan mendorong mereka untuk saling berbagi (sharing) pengetahuan, pengalaman, dan pemikiran tentang pesan dakwah.

Dua perspektif di atas mengenai posisi mad'u pertama sebagai obyek dan sasaran dakwah dan kedua menempatkan mad'u sebagai mitra dakwah memang merupakan dinamika aktifitas dakwah di masyarakat. Dinamisasi ini disinyalir dilihat dari sudut pandang keilmuan dakwah yang lebih melihat dalam tataran teologis dan sosiologis. Tetapi butuh ditambahkan perspektif lain untuk melihat posisi mad'u sebagai masyarakat informasi yang sudah terpapar beragam informasi maupun pesan agama (pesan dakwah) dari berbagai media yang ada. Oleh karena itu perlu kiranya membahas bagaimana karakteristik mad'u dalam kajian ilmu komunikasi dan uraiannya seperti di bawah ini.

\section{Karakteristik Mad'u Pasif dan Aktif Perspektif Denis McQuail}

Pembahasan mengenai mad'u atau audien dakwah bisa dipetakan menjadi dua yaitu mad'u pasif dan mad'u aktif. Pengkategorian mad'u pasif-aktif ini memang terinspirasi oleh kajian ilmu komunikasi dari Denis McQuail tentang audiens komunikasi. ${ }^{5}$ McQuail mengkategorikan perkembangan konsep audiens sejalan dengan perkembangan media. Setiap perkembangan media inilah yang

\footnotetext{
${ }^{4}$ Moh Ali Aziz, Ilmu Dakwah, edisi revisi, (Jakarta : Kencana Prenada), hlm. 263.

${ }^{5}$ Denis McQuail, Teori Komunikasi Massa Jilid 1 (Jakarta : Erlangga), hlm. 147.
} 
menentukan perbedaan-perbedaan posisi audiens. Uraian McQuail sebagaimana di bawah ini.

Pertama, karakter audiens di pertunjukan teater, di sini audiens sebagai penonton atau pendengar yang terorganisir, kehadiran audiens dan performer berada dalam ruang dan waktu yang sama. Kedua, seiring berkembangnya media cetak audiens dipahami sebagai pembaca 'setia' media cetak tertentu. Dalam konteks ini, audiens terpisah secara ruang dan waktu dengan produsen media maupun dengan audiens lainnya. Ketiga, kehadiran Film mengembalikan konsep audiens seperti pada awal kemunculannya, yaitu keterikatan ruang dan waktu antara audiens dengan performer (dalam hal ini penayangan film). Perkembangan ini melahirkan konsep 'mass audience' yang merujuk pada pengertian penerimaan pesan yang sama oleh individu dalam jumlah besar. Selanjutnya, Keempat, pengertian audiens kembali bergeser seiring dengan kemunculan media elektronik seperti televisi dan radio, di kategori ini ada tiga elemen penting dari komunikasi massa. (1) konten berskala luas, heterogen, dan mempunyai audiens yang anonim; (2) konten ditransmisikan secara luas dan mencapai audiens secara serentak; (3) komunikator tergabung dalam organisasi yang kompleks dan melibatkan biaya besar dalam produksi kontennya. Kelima, audiens bermetamorfosis setelah adanya new media. Berikut ini adalah beberapa dimensi pokok dari audiens yang dapat menjadi landasan untuk melihat perubahan bentuk audiens di era new media. Seperti (1)Degree of activity or passivity; (2)Degree of interactivity and interchangeability; (3)Size and Duration; (4)Locadness in space; (5)Group Character (Social/cultural identity); (6)Simultanity of contact with source; (7) Heterogeneity of composition; (8) Social relations between sender and receiver; (9) Message vs social/behavioural definition of situation; (10) Degree of social presence; (11) Sociability of context of use.

Kehadiran new media juga secara signifikan membawa perubahan pola produksi, distribusi, maupun konsumsi pesan. Perubahan-perubahan yang terjadi terkait dengan media baru, membawa perubahan pada karakter audiens, terkait 
dengan relasi antara media dengan audiens. Pada awalnya, relasi antara media dengan audiens adalah relasi antara sender dan receiver. Media berperan sebagai produsen yang mentrasmisikan pesan kepada audiens. Dalam konteks ini, audiens bersifat pasif menerima pesan yang dikirimkan oleh media. Hal ini disebabkan oleh keterbatasan teknologi yang tidak memungkinkan adanya komunikasi langsung antara sender dan receiver. Komunikasi hanya berjalan satu arah saja. Namun, perkembangan teknologi mampu mengalahkan keterbatasan tersebut. Pada era digital, beriring perkembangan computer based system, bentuk media interaktif mulai berkembang.

Perkembangan konsep audiens akibat dari perkembangan media membawa beberapa konsekuensi menarik. Telah banyak disinggung sebelumnya, audiens tidak bisa lagi dipahami sebagai receiver, tetapi lebih pada perannya sebagai partisipan. Namun, kecenderungan ini dilihat oleh penulis tidak sepenuhnya berdampak positif pada audiens. Derajat interaktivitas yang lebih tinggi dalam media baru dianggap mempunyai peluang untuk menyeimbangkan kekuasaan audiens dengan media, yang selama ini berperan sebagai pengontrol. Partisipasi aktif dari audiens dianggap sebagai 'kejayaan' baru bagi individu-individu yang selama ini hanya bertindak sebagai audiens pasif saja. Hanya saja, ada beberapa hal lain yang membuat optimisme itu menjadi kabur. Sepertinya halnya radikalisme, informasi hoaks dan echo chamber yang harus diperhatikan dalam dalam aktifitas dakwah.

\section{Potret dan Segmentasi Mad'u Dalam Perkembangan Media di Indonesia}

Penulis menggunakan lima konsep audiens yang ditawarkan Dennis McQuail untuk mendeskripsikan potret dan segmentasi mad'u di Indonesia. Konsep pertama, audiens sebagai penonton atau pendengar yang terorganisir, kehadiran audiens dan performer berada dalam ruang dan waktu yang sama. Konsep audien ini bisa disejajarkan dengan aktifitas dakwah dalam kategori tabligh di Indonesia. Masyarakat Indonesia yang lebih unggul dalam budaya lisan lebih cenderung 
menggunakan tabligh sebagai aktifitas dakwah. Sejak kedatangan Islam di Indonesia, kemudian era Walisongo sampai sekarang dakwah versi tabligh ini mendominasi aktifitas dakwah di Indonesia. Kehadiran da'i dan mad'u dalam suatu forum kajian keagamaan, pengajian, majelis taklim berada dalam ruang dan waktu yang sama. Penyampaian pesan dakwah oleh da'i di kategori ini bersifat linier atau searah, dan da'i mempunyai durasi waktu untuk mendominasi penyampaian pesannya. Penggunaan media di kategori ini memang masih tradisional, karena da'i-mad'u berada dalam ruang dan waktu yang sama, jadi hanya membutuhkan mikrofon dan sound system yang memadai. Tetapi ketika ditarik dengan fenomena sekarang, tabligh ini juga bermetamorfosa mengikuti perkembangan media yang terjadi. Fenomena ceramah atau pengajian oleh da'i tertentu dan di wilayah tertentu dan kemudian direkam melalui audio, audio-visual dan dengan sistem sewa-kerjasama pada akhirnya tablig da'i tertentu bisa diputar di radio tertentu. Televisi pun juga mempunyai kesempatan untuk menayangkan tabligh baik secara langsung (live) maupun memutar rekaman (taping) dengan perpedoman tarif dan logika media yang bersifat tidak gratis. Versi lengkap rekaman tabligh ini juga bisa dinikmati di beberapa channel youtube, begitu pula potongan kutipan da'i tertentu juga bisa dilihat di akun instagram. Metamorfosis tabligh di media ini memang mengikuti menyesuaikan dengan format konten media, hanya saja apabila dianalisis sebenarnya posisi da'i dan mad'u tetaplah sama, da'i sebagai sender aktif dan mad'u sebagai audien pasif.

Konsep kedua, audien dipahami sebagai pembaca 'setia' media cetak tertentu. Dalam konteks ini, audiens terpisah secara ruang dan waktu dengan produsen media maupun dengan audiens lainnya. Aktifitas dakwah tidak hanya berkembang di wilayah tabligh secara lisan saja tetapi juga masuk ke ranah media cetak atau dikenal dengan dakwah bi al-qalam/kitabah dan apabila ditelusuri banyak ditampilkan dalam penulisan sastra Islami,dan jurnalisme Islami ${ }^{6}$.

\footnotetext{
${ }^{6}$ Jurnalisme Islami dapat dimaknai sebagai proses pemberitaan/ pelaporan tentang berbagai hal yang syarat muatan dan sosialisasi nilai-nilai Islam. Kiki Zakiah "Profesionalisme Pers Islam
} 
Menurut Abdul Hadi W.M perkembangan sastra Islami selanjutnya muncul tahun 50-an dan awal 60-an. ${ }^{7}$ Beberapa tokoh sastra di era ini banyak yang berkarya pada jenis puisi, sedangkan jenis sastra lainnya berupa prosa dalam format novel ditulis oleh Hamka dengan karya novelnya Tenggelamnya Kapal Van der Wijk. ${ }^{8}$ Karya Hamka selanjutnya berjudul Di Bawah Lindungan Ka'bah telah mencapai kepupolerannya pada masanya kemudian diadaptasi dan diangkat dalam film layar lebar dengan judul sama pada tahun 2011. Selain Hamka, A. A Navis juga menelurkan karya cerpen yang berjudul Robohnya Surau Kami. ${ }^{9}$ Tahap selanjutnya pada tahun 1998, setelah dua minggu pasca lengsernya Presiden Soeharto sastra Indonesia banyak mengusung tema "sastra wangi", Perkembangan sastra wangi kemudian coba dilawan Helvy Tiana Rosa ${ }^{11}$, juga digaungkan oleh Abiedah El Khalieqy, Titis Baseno dan Ratna Indraswari.Perkembangan sastra Islami dalam bentuk novel di Indonesia semakin hari terus berubah. Kini, mulai menjamur novel yang mengambil inspirasi tokohtokoh yang mengubah dunia, mulai dari novel biografis ilmuwan, ulama, dan

Dalam Menjalankan Jurnalisme Dakwah" dalam Ilmu Komunikasi Sekarang dan Tantangan Masa Depan (Jakarta : Kencana, 2011), 110. Bandingkan dengan Suf Kasman, Jurnalisme Universal: Menelusuri Prinsip-Prinsip Da'wah bi al-Qalam dalam Al-Qur'an (Jakarta : Teraju, 2004), 50-51.

${ }^{7}$ Nama-nama seperti Abdul Muis, Amir Hamzah, Hamka, Ali Hajsmy, Abu Hanifah, Bachrum Rangkuti, Samadi dan Armin Pane disebut sebagai penulis sastra Islami. Generasi penulis selanjutnya yaitu : Mohammad Diponegoro, AA Navis, Djamil Suherman, Saribi Afn, Taufik Ismail, Ajip Rosidi, Goenawan Mohammad, Mahbub Junaidi, Alwan Rafsiri, Mohamad Ali dan Asrul Sani. Lihat di Mohd Faizal Musa, "Fenomena Sastera Islam di Indonesia", International Journal of the Malay World and Civilisation, Iman 30 (1), (2012), hlm. 43.

${ }^{8}$ HB Jassin, Sastra Indonesia Sebagai Warga Sastra Dunia (Jakarta : Gramedia, 1983), ix

9 Burhan Nurgiyantoro, Teori Pengkajian Fiksi (Yogyakarta : Gadjah Mada University Press, 2010), hlm. 72.

${ }^{10}$ Sastra wangi bermunculan setelah lengsernya Presiden Soeharto karena sebelumnya penulisan sastra bertema perempuan sangat diawasi Pemerintahan Orde Baru. Ideologi Orde Baru menempatkan perempuan harus hidup sesuai dengan kodratnya "kodrat perempuan/ ibuisme" yaitu gerak perempuan terbatas bidang domestik seperti mengurus rumah tangga dan mengasuh anak-anak. Selain itu wanita yang tidak anggun dan menyalahi "kodrat perempuan" dianggap telah menyalahi susila. Maka dari itu gerakan sastra wangi berupaya melakukan perlawanan atas tindakan represif Orde baru pada wanita. Tokoh-tokohnya seperti Oka Rusmini, Ayu Utami, Fira Basuki, Djenar Maesa Ayu, Dewi Lestari, Dinar Rahayu, dan Nova Riyanti Yusuf, Lihat, Monika Arnez \& Dewojati, "Sexuality, Morality and the Female Role: Observations on Recent Indonesian Women's Literature” Asiatische Studien / Études Asiatiques, 64(1), (2010), 10-11.

${ }^{11}$ Diah Ariani Arimbi, Reading Contemporary Indonesia Woman Muslim Writer : Representasion, Identity and Religion of Muslim Woman in Indonesian Fiction (Amsterdam : Amsterdam University Press, 2009), 85. 
tokoh pergerakan politik. Seperti Novel Lelaki Penggenggam Hujan merupakan biografi Nabi Muhammad Saw yang ditulis Tasaro GK ${ }^{12}$, Novel biografis KH Ahmad Dahlan berjudul Sang Pencerah oleh Akmal Nasery Basral yang merupakan adaptasi dari film Sang Pencerah tahun $2010^{13}$, Novel Biografis KH Hasyim Asyari berjudul Sang Penakluk Badai ${ }^{14}$ dan karya-karya Tereliye.

Jurnalisme Islami juga berupaya merebut segmen pembaca muslim (audien)di Indonesia. Di era setelah reformasi muncul nya majalah Ummi, Annida, Sabili, Hidayatulah dan harian Republika dengan oplah pembaca yang fantastis. Misalnya majalah Sabili dianggap sebagai media Islam terbesar di Indonesia dan dipandang sebagai contoh paling menonjol dari keberagaman konten dan pembaca yang ada di Indonesia. ${ }^{15}$ Pada 2002 dan 2003, Sabili pernah menjual lebih dari 140.000 eksemplar per edisi.Pada 2005, mereka yang berada di dalam media Islam melaporkan ketidakmampuannya memperoleh iklan komersial. Pada 2008, sirkulasi Sabili anjlok hingga kisaran 40.000 eksemplar. Pada akhirnya Sabili dan Hidayatullah tunduk logika media karena tidak mempunyai model bisnis atau korporasi yang bisa mendapatkan iklan. ${ }^{16}$

Karena tidak bisa menghasilkan iklan untuk menopang operasional media, sebagian besar media Islam fundamentalis di Indonesia berpindah ke ruang maya, ruang yang lebih murah, lebih anonim, dan bisa menggabungkan berbagai sudut

\footnotetext{
${ }^{12}$ Tasaro mengemas cerita faktual tentang kehidupan Rasulullah Saw, tentang cara hidup, hingga kebijaksanaan dan kewibawaan rasul. Selain itu, Tasaro juga menyisipkan satu cerita fiksi yang berada pada masa yang sama dengan masa kenabian Rasul Muhammad Saw. Tasaro GK, Muhammad: Lelaki Penggenggam Hujan (Jakarta : Bentang Pustaka, 2010),

13 Akmal Nasery Basral membuat sebuah terobosan dengan membuat sebuah novel yang mengadopsi dari sebuah skenario film yang sudah jadi, berjudul Sang Pencerah (Novelisasi Kehidupan K.H. Ahmad Dahlan dan Perjuangannya mendirikan Muhammadiyah). Akmal Nasery Basral, Sang Pencerah (Jakarta : Mizan, 2010), hlm. iii.

${ }^{14}$ Aguk Irawan mencoba menyingkap detail karisma dan keagungan KH. Hasyim Asyari yang selama ini hanya direduksi sebagai tokoh besar di kalangan Ormas Nahdhatul Ulama (NU) yang perannya sering hanya diketahui sekedar membela Aswaja dan menolak keras Wahabisme. Lebih dari itu, dengan mengangkat perjuangan dan sumbangsihnya di bidang pendidikan.

${ }^{15}$ Budi Irawanto, "Riding Waves of Changes : Islamic Press in Post Authotarian Indonesia, dalam Hill dan Sen (eds), Politic and Media, hlm 70-72.

${ }^{16}$ Ross Tapsell, Kuasa Media di Indonesia ; Kaum Oligarki, Warga dan Revolusi Digital (Tangerang : Marjin kiri), hlm.109
} 
pandang dari tempat lain di dunia Islam. Media Islam yang moderat juga pelanpelan menghilang dari pasaran karena ketidakmampuan memperoleh iklan.

Ketiga, konsep audiens dalam Film, yaitu keterikatan ruang dan waktu antara audiens dengan performer (dalam hal ini penayangan film). Perkembangan ini melahirkan konsep 'mass audience' yang merujuk pada pengertian penerimaan pesan yang sama oleh individu dalam jumlah besar. Aktifitas dakwah juga pernah mencari segmentasi penonton dan juga mencicipi kesuksesan produksi film, seperti film Ayat-Ayat Cinta, Ketika Cinta Bertasbih, Wanita Berkalung Sorban, Emak Ingin Naik Haji, Tanda Tanya, 99 Cahaya di Langit Eropa, dan beberapa film biopic tokoh Islam seperti halnya Sang Pencerah, Sang Kiai.

Fenomena film Islami ini bisa dianalisis menggunakan dua perspektif, yaitu pertama dari perspektif idealisme dakwah dan kedua dari perspektif komodifikasi agama. ${ }^{17}$ Dalam perspektif idealisme dakwah, film-film bertemakan Islam bisa dimaknai sebagai dakwah yang dikemas melalui artefak budaya dengan memanfaatkan teknologi senimatik. Sementara dalam perspektif komodifikasi agama, film-film bertemakan Islam sesungguhnya merupakan komodifikasi atas agama oleh produksi massa dalam bentuk budaya populer. Dalam hal ini Islam mengalami komodifikasi ketika kepercayaan dan simbol-simbolnya berubah menjadi "komoditas yang bisa dibeli dan dijual demi keuntungan". Dalam konteks ini, komodifikasi agama melalui film-film bertemakan Islam cenderung melegitimasi budaya populer di kalangan umat Islam, utamanya kaum muda Islam. Agama pada gilirannya hanya dikonstruksi untuk memenuhi kepentingan industri (pasar) yang menganut prinsip supply dan demand.

Kesuksesan film Islami yang bertemakan cinta, gender, dan kehebatan tokoh Islam di beberapa film biopic ini di satu sisi sebagai angin segar bagi da'i untuk masuk ke ranah sinema dengan menawarkan tema pesan-pesan Islami, tetapi di sisi lain juga mendapat kritikan pedas karena dirasa memperlakukan

\footnotetext{
${ }^{17}$ Hakim Syah, "DAKWAH DALAM FILM ISLAM DI INDONESIA (Antara Idealisme Dakwah dan Komodifikasi Agama)",Jurnal Dakwah, Vol. XIV, No. 2 Tahun 2013, hlm. 263.
} 
Islam sebagai komoditas. Selain itu budaya latah sinema Indonesia yang hanya mengusung representasi tema Islami yang hampir sama yaitu tentang cinta, hidup susah-kaya, personifikasi yang berlebihan terhadap tokoh Islam yang difilmkan. Pada akhirnya film dengan tema-tema Islam terjadi kejenuhan kurang menarik dan juga ditinggalkan oleh audien.

Keempat, pengertian audiens kembali bergeser seiring dengan kemunculan media elektronik seperti televisi dan radio. Media arus utama Indonesia tidak hanya mengakomodasi tema-tema Islam, tetapi juga formatnya sudah dikomodifikasi. Misalnya, sinetron dan drama televisi tentang ibu rumah tangga yang shalihah, ditambah dengan maraknya pengajian, motivasi dan tayangan pendidikan azab bertubi-tubi bagi pendosa. Ini berarti pengarusutamaan Islam ke budaya nasional tidak melalui sudut pandang konservatif, melainkan dari tayangan-tayangan bertema Islam yang menyatu dengan format produksi tayangan televisi yang sekuler. Inaya Rakhmani ${ }^{18}$ berpendapat bahwa tema-tema Islam mengalami komodifikasi, pesan-pesan relijius diubah menjadi produk jualan. Pada saat yang sama, para pemilik dan praktisi televisi sangat berhati-hati menggambarkan agama di tayangan televisi karena takut ancaman kelompok Islam fundamentalis atau takut kehilangan mayoritas penonton Muslim mereka.

Kelima, audiens bermetamorfosis setelah adanya new media (baca internet). Aktifitas dakwah di internet dapat dilihat dari ekspresi dan representasi Islam di internet. Aktifitas dakwah meliputi konteks komunikasi keagamaan yang dimediasi oleh fitur-fitur internet sebagai medium komunikasi, gerakan-gerakan sosial keagamaan yang muncul melalui komunitas-komunitas internet, dan upaya sistematis untuk memfasilitasi interaksi dakwah yang dilakukan secara online.

Ada jutaan situs yang dapat diidentifikasi sebagai situs dakwah, baik secara eksplisit maupun implisit. Secara eksplisit, konten-konten dalam situs dakwah biasanya berisi informasi dunia Islam, dialog seputar masalah-masalah

\footnotetext{
${ }^{18}$ Inaya Rakhmani, Rethinking Indonesian Nationalism in an Age of Comercial Islam,(Murdoch University Press, 2013), hlm. 28
} 
keagamaan, buku-buku dengan tema keislaman, fasilitas untuk unduh software Islami, dan sejumlah layanan lain yang berhubungan dengan Islam. Situs-situs spesifik ini belum termasuk komunitas-komunitas Islam yang bermunculan melalui situs-situs media sosial dan forum-forum diskusi yang pada umumnya merupakan salahsatu fitur khusus yang bersifat umum.

Secara teknis fenomena aktifisme dakwah di internet dapat diidentifikasi melalui beragam ekspresi secara umum dapat dikategorikan dalam 5 (lima) kategori besar $^{19}$, yakni portal Islam, media sosial Islam, file sharing, chat Islam dan aplikasi Islam di playstore.

Konsekwensi keberadaan new media bisa mengubah jejaring muslim, mengubah public sphere Islam dan pergeseran otoritas keagamaan tradisional. ${ }^{20}$ New media juga membawa perubahan pada aspek pemikiran, fatwa-fatwa, dan pengamalan keagamaan, serta hubungan-hubungan yang terjalin atas dasar normanorma keagamaan. Kecenderungan ini merupakan tantangan sekaligus harapan bagi agama-agama ${ }^{21}$ Pergeseran otoritas keagamaan dan relasi hubungan antara pengikut dengan tokoh-tokoh atau pemimpin agama yang menjadi panutan dalam kehidupan sehari-hari. Sebelumnya otoritas keagamaan hanya dimiliki oleh para ulama, ustadz, kiyai. Sekarang ini mengalami pergeseran ke media baru yang memungkinkan setiap orang bisa dengan mudah mengakses pengetahuan menurut selera dan kebutuhan masing-masing. Dengan adanya media baru seseorang cukup mengetik di kolom pencarian (search), maupun di aplikasi Islam di playstore akan ditemukan berbagai macam solusi pesoalan. Berbagai macam persoalan tidak harus bertanya langsung kepada ulama. Fatwa-fatwa keagamaan tidak lagi hanya dimiliki oleh ulama konvensional, tetapi dengan mudah setiap

\footnotetext{
${ }^{19}$ Moch. Fakhruroji, Dakwah di Era Media Baru (Bandung : Simbiosa Rekatama, 2017), hlm. 197. 20 A.M Iqbal, 2014."Internet, Identity and Islamic Movement : the Case Salafim in Indonesia, (Islamika Indonesiana, 1:1, 2014)”, hlm. 81-82.

${ }^{21}$ Jinan Muthoharun, 2013, "Intervensi New Media dan Impersonalisasi Otoritas Keagamaan di Indonesia, Komunikasi Islam Vol.3 No.2 Desember 2013, hlm. 324.
} 
orang bisa menemukan jawaban dan mengambil keputusan berdasarkan informasi yang tersedia di media.

Konsekwensi selanjutnya dari keberadaan new media adalah perang wacana dan perebutan penguasaan opini dari media yang merepresentasikan diri sebagai media Islam di Indonesia turut mengkotak-kotakkan identitas komunitas Islam tertentu. Silang pendapat dan counter attack wacana kerap dipertontonkan baik di ranah media Islam online maupun di media sosial. Fenomena ini merupakan konsekwensi dari keterbukaan informasi, di mana setiap orang bebas mengakses informasi, berkomentar, dan menyebarkan gagasannya di internet. Atas dasar inilah Kementerian Agama, beberapa pondok pesantren di Indonesia mengkampanyekan literasi media atau santri melek media. Literasi media ini diharapkan bisa membuka wacana umat agar bisa menjadi audiens aktif dan kritis dibanding menjadi audiens pasif dalam menerima sebaran konten Islami. Adanya penguasaan masyarakat dalam literasi media ini juga untuk menepis beberapa informasi hoaks tentang agama yang bisa memecah belah umat, dan juga menepis echo chambers yaitu ruang gema yang berisi pandangan orang-orang yang beranggapan sama dan satu selera sehingga tidak menghasilkan dialog yang baik.

\section{PENUTUP}

Aktifitas dakwah pada dasarnya selalu bersifat segmented, dimana pesan dan pola dakwah akan selalu berusaha disesuaikan dengan konteks khalayak. Khalayak atau mad'u selalu berubah mengikuti perkembangan media komunikasi yang ada. Mad'u pasif dikategorikan ketika berada dalam aktifitas dakwah yang berupa tablig dan dakwah di media massa, sedangkan mad'u aktif memungkinkan menjadi produsen-konsumen informasi dikarenakan difasilitasi teknologi new media. Pengkategorian mad'u pasif-aktif ini harus diperhatikan da'i agar dakwah selalu melintasi zaman meskipun ada beberapa konsekwensi yang menyertainya. 


\section{Daftar Rujukan}

A.M Iqbal. "Internet, Identity and Islamic Movement : the Case Salafim in Indonesia, Islamika Indonesiana, 1:1, 2014.

Arimbi, Diah Ariani. Reading Contemporary Indonesia Woman Muslim Writer : Representasion, Identity and Religion of Muslim Woman in Indonesian Fiction, Amsterdam : Amsterdam University Press, 2009.

Aziz, Moh Ali. Ilmu Dakwah, edisi revisi, Jakarta : Kencana Prenada.

Fakhruroji, Moch. Dakwah di Era Media Baru, Bandung, Simbiosa Rekatama, 2017.

Irawanto, Budi. "Riding Waves of Changes : Islamic Press in Post Authotarian Indonesia, dalam Hill dan Sen (eds), Politic and Media, 2011.

Jassin, HB. Sastra Indonesia Sebagai Warga Sastra Dunia Jakarta : Gramedia, 1983.

Kasman, Suf. Jurnalisme Universal: Menelusuri Prinsip-Prinsip Da'wah bi alQalam dalam Al-Qur'an. Jakarta : Teraju, 2004

McQuail, Denis. Teori Komunikasi Massa Jilid 1, Jakarta : Erlangga, 2014.

Mohd Faizal Musa, "Fenomena Sastera Islam di Indonesia”, International Journal of the Malay World and Civilisation.

Monika Arnez \& Dewojati, "Sexuality, Morality and the Female Role: Observations on Recent Indonesian Women's Literature" Asiatische Studien / Études Asiatiques, 64 (1), (2010)

Muthoharun, Jinan. 2013, "Intervensi New Media dan Impersonalisasi Otoritas Keagamaan di Indonesia, Komunikasi Islam Vol.3 No.2 Desember 2013.

Nurgiyantoro, Burhan. Teori Pengkajian Fiksi Yogyakarta : Gadjah Mada University Press, 2010

Rakhmani, Inaya. Rethinking Indonesian Nationalism in an Age of Comercial Islam, Murdoch University Press, 2013.

Saputra, Wahidin. Pengantar lmu Dakwah, Jakarta ; Raja Grafindo, 2011.

Syah, Hakim. "DAKWAH DALAM FILM ISLAM DI INDONESIA (Antara Idealisme Dakwah dan Komodifikasi Agama)", Jurnal Dakwah, Vol. XIV, No. 2 Tahun 2013

Tapsell, Ross. Kuasa Media di Indonesia ; Kaum Oligarki, Warga dan Revolusi Digital, Tangerang : Marjin kiri.

Zakiah, Kiki. "Profesionalisme Pers Islam Dalam Menjalankan Jurnalisme Dakwah" dalam Ilmu Komunikasi Sekarang dan Tantangan Masa Depan Jakarta : Kencana, 2011. 